\title{
MAPPING SALT-LOADS OF THE MURRAY RIVER, AUSTRALIA, USING AIRBORNE AND IN-RIVER ELECTROMAGNETIC METHODS.
}

\author{
A. Fitzpatrick, CSIRO/CRCLEME,Perth, Australia \\ T. J. Munday, CSIRO/CRCLEME, Australia \\ V. Berens, DWLBC/CSIRO, Adelaide, Australia \\ M.A. Hatch, University of Adelaide/CRCLEME, Adelaide, Australia \\ A. L. Telfer, AWE, Adelaide, Australia
}

\begin{abstract}
Salinity in the River Murray and in adjacent floodplains of south-central Australia, has important environmental, economic and social consequences. Methods to monitor the temporal state of river and particularly river-groundwater interactions, have been in place for many years now. However, few have the capacity to define variability at a resolution appropriate for developing effective salinity management strategies, such as salt interception schemes. The use of geophysical methods for rapid high resolution mapping of river sediments has been successfully trialed in Australia, particularly using the "in stream" NanoTEM, a time domain ground EM system, deployed in a boat with the transmitter and receiver towed behind on a rigid floating boom. More recently, tests have been conducted using two different helicopter EM systems; a frequency domain EM system (FDHEM) and a time-domain EM system (TDHEM). Comparisons between conductivity-depth sections derived from the "in stream" NanoTEM and the airborne datasets suggest that the different approaches are comparable.

This paper examines the potential of using the FDHEM RESOLVE system as basis for mapping reaches of the river that contribute to elevated salt loads in the Murray River to the south east of Mildura in Victoria. The advantages of the airborne systems become more apparent when data coverage and acquisition costs are considered, particularly in a situation where a parallel swath approached is employed. This entails the acquisition of adjacent lines of EM data along the centre and along the margins of the river. We suggest this approach provides for a better understanding of recharge and discharge processes and links between the floodplain and the main-river channel. Compared with data acquired along the river alone, this study demonstrated our ability to use Helicopter EM data to map losing and gaining (from a salt load perspective) stretches of the river and to provide insight into which parts of the groundwater-floodplain system were significant contributors to river salt loads. The rapid acquisition of airborne EM data makes these systems more suited to providing temporal snapshots of a river-floodplain environment during dramatic climatic events, such as flooding. In the Murray basin this may assist our understanding of how salt stores are mobilised during such occasions.
\end{abstract}

\section{Introduction}

The Murray River, situated in the southeast of Australia, has become extensively salinised, reflecting, in large part, increases in recharge to the naturally saline groundwater system from the irrigation that flanks the river, and a consequential increase in its discharge due to the regulation of river flow by weirs and increased water extraction. The issue is compounded by a lack of flooding (which helps flush the near surface soils) and rising saline groundwater. In order to manage the problem and to protect the ecology and biodiversity along the river, a range of management strategies are being employed including the development of salt interception schemes (SIS), targeted spear point pumping to lower groundwater under vulnerable tree communities, injection of fresh water in the same regions, and artificial flooding or environmental irrigation. 
However, there is an accompanying need to acquire biophysical data that permit the effectiveness of these strategies to be assessed, calibrated and monitored. Geophysical, particularly electrical and electromagnetic, methods have a demonstrated potential to provide detailed spatiotemporal information on the distribution of salinity in soils and groundwater, thereby indicating spatial patterns of groundwater evapotranspiration and base flow across salinising floodplains that characterise the lower River Murray (e.g. Munday et al. 2006). Similarly they have considerable potential to map variations in the salt loads of river bed sediments in the Murray as was demonstrated by Barrett et al. (2005) and Telfer et al. (2004). They described the use of a towed TEM array (the Zonge NanoTEM) to determine the salinity of water contained in the top few metres of alluvial sediments immediately beneath the River Murray, as an alternative to Run-of-River surveys which involves the electrical conductivity measurement of river water (Porter 1997). The application of airborne systems for comparable applications has seen limited use, despite recent improvements in their calibration allied with improved interpretation methods. Their value for river salinity surveys was flagged in a recent US study described by Paine et al. (2006).

We sought to explore this potential further, and compare the merits of undertaking "in river" surveys with airborne EM systems as an alternative to floating towed TEM arrays in the context of the Murray River in Australia. In this paper we compare data acquired in 2006 from an "in river" NanoTEM survey with data from helicopter EM system for a stretch of the Murray River in Victoria, Australia. The data from the two systems was acquired over a 2 month period in mid 2006.

\section{Study area location and hydrogeology}

The area chosen for the "in river" trail of the HEM system is located south-east of Mildura in Victoria (Figure. 1), and formed part of a more extensive helicopter EM survey with the RESOLVE system (Figure 2) undertaken in the Sunraysia area. This reach of the river covers the Kings Billabong and Red Cliffs areas and is generally regarded as a gaining reach where the groundwater, sourced from

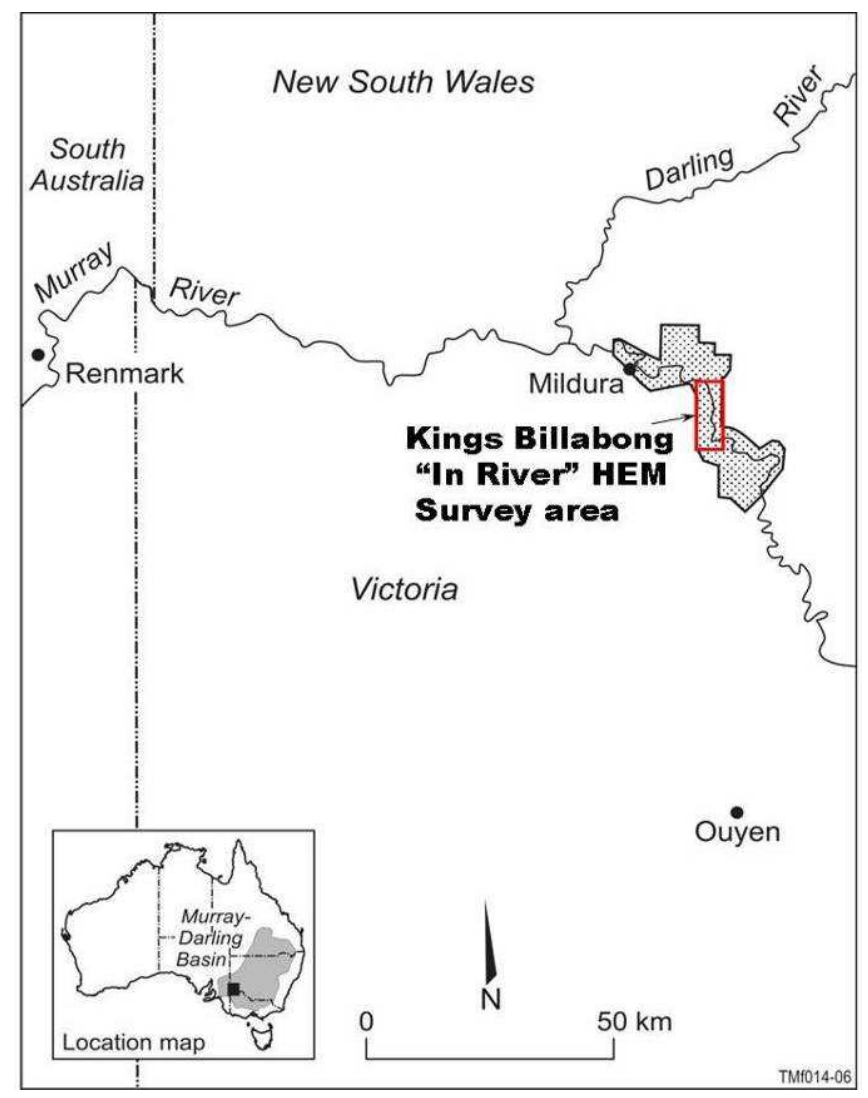

Figure 1: Location of the trial "in-river" HEM survey in the Kings Billabong reach of Murray River. The trail was conducted as part of a broader EM survey (shown as the shaded area).

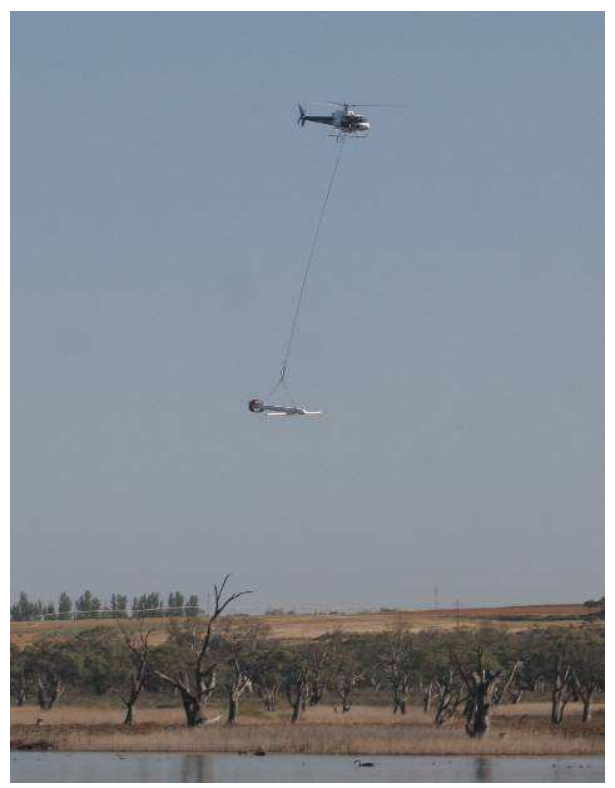

Figure 2: The RESOLVE FDHEM system 


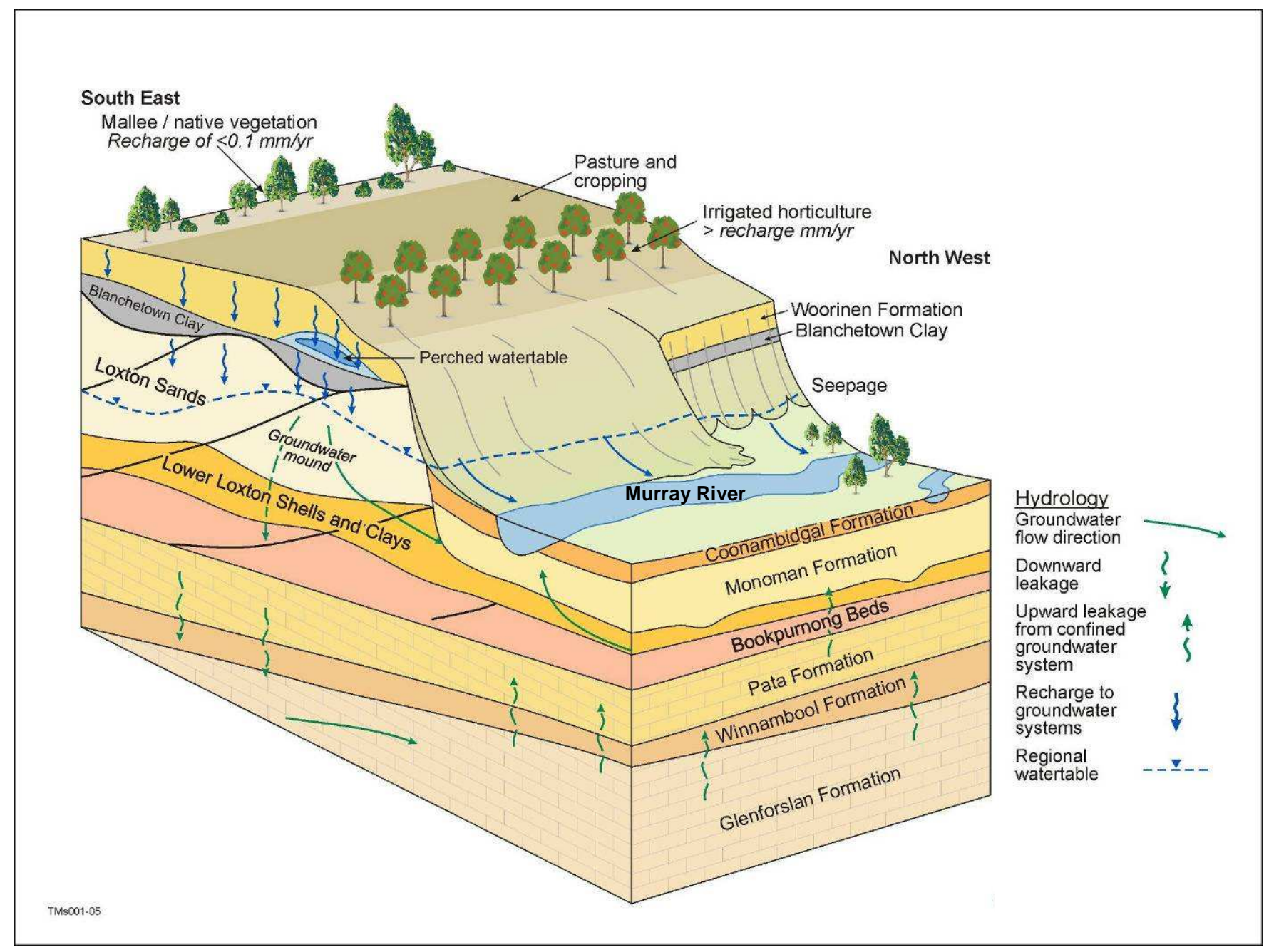

Figure 3: Schematic diagram showing how the excess recharge from irrigation on highland areas adjacent to the floodplain leads to the formation of a groundwater mound, and an increased hydraulic gradient which displaces the natural saline groundwater towards the floodplain and ultimately into the river.

a regional flux and irrigation induced groundwater mounds, discharges into the floodplain alluvium and into the river. In this area, the floodplain comprises a broad $(\sim 5 \mathrm{~km}$ wide $)$, undulating landscape of cutoff meanders, terraces and former river channels incised into the surrounding landscape.

Groundwater is generally found within $2 \mathrm{~m}$ of the floodplain surface. The hydrogeology of this reach of the river is typical of the eastern part of the lower River Murray. Floodplain sediments comprise the Coonambidgal Clay (ranges from 3 to $7 \mathrm{~m}$ thick), which overly the Monoman Formation (sandy sediments approximately $7 \mathrm{~m}$ thick in this area). The cliffs adjacent the floodplains consist of a layer of Woorinen Sands over Blanchetown Clay, overlying the Loxton-Parilla Sands which can be up to $35 \mathrm{~m}$ thick. The whole area is underlain by the Bookpurnong Beds and sediments of the Murray Group. This is illustrated schematically in Figure 3. 
Groundwater salinity in the floodplain sediments exceeds $30000 \mathrm{mg} / \mathrm{L}$ in places, while irrigation recharge salinity is typically $7000 \mathrm{mg} / \mathrm{L}$. Where irrigation has been developed in areas adjacent to the floodplain, excess recharge has led to the formation of a groundwater mound, which displaces saline groundwater towards the floodplain and ultimately to the river (Figure 3). The Murray River itself is incised into the sands of the Monoman Formation.

\section{Methods}

\section{“In-river" EM acquisition and processing}

"In-river" EM data acquired for the Kings Billabong -Red Cliffs reach of the River Murray (Figure 1), were collected using a floating version of Zonge Engineering's land-based NanoTEM system (Telfer et al. 2006). A single-turn transmitting antenna $(7.5 \mathrm{~m} \times 7.5 \mathrm{~m})$ was mounted on a stiff PVC framework of four floating pontoons, with a receiving antenna $(2.5 \mathrm{~m} \times 2.5 \mathrm{~m})$ positioned in the centre of the loop frame. The pontoon was towed behind boat. Data were acquired in a nearly continuous mode every 4 seconds using 64 cycles at a repetition rate of 32 hertz and a sampling rate of 1.2 or 1.6 microseconds. An average boat speed of $6-8 \mathrm{~km} / \mathrm{h}$ resulted in a TEM reading approximately every 7 to 10 metres along the river. Progress along the river was determined with a GPS/sounder which logged position(non-differential) and water depth approximately every 10 metres. All three data sets were time stamped and synchronised, resulting in an accurately located TEM sounding and associated water depth (Telfer et al. 2006). The survey was completed in early June 2006.

Time stamped raw TEM and GPS data (with water depths) are combined into a single file and are processed using Zonge's 1D TEM inversion, STEMINV (MacInnes and Raymond, 2001). This transforms time vs. signal magnitude into modelled conductivity as a function of depth. This inverted data set is post-processed to remove data with erroneous spatial information and to assign a survey distance to each TEM station (or record).

\section{Helicopter Electromagnetics (HEM) data acquisition and processing}

The "in-river" HEM data were acquired as part of a broader EM survey in August 2006 (Figure 1), which used the Fugro RESOLVE frequency domain helicopter EM system (Figure 2), six frequency EM system mounted in a bird towed beneath a helicopter at a nominal altitude of $30 \mathrm{~m}$. The bird contains horizontal coplanar coils, and in the Kings Billabong "in-river" survey measured an EM response at $390 \mathrm{~Hz}, 1798 \mathrm{~Hz}, 8177 \mathrm{~Hz}, 39470 \mathrm{~Hz}$ and $132700 \mathrm{~Hz}$. It also has one coaxial coil pair which measured a response at $3242 \mathrm{~Hz}$. RESOLVE is a digital frequency domain EM system with internal calibration coils for automatic phase and gain calibration in the air. An attitude system measuring pitch, roll was added to the bird to assist in producing accurate conductivity models of the subsurface, although data presented here have not been corrected for bird attitude variations.

Three parallel lines of data were acquired along the Murray River with a line spacing of $\sim 50 \mathrm{~m}$ (Figure 4). Conductivity depth images (CDI's) of the RESOLVE data were produced using EMFlow software (Macnae et al., 1998). Interval conductivity slices were then calculated for $2 \mathrm{~m}$ depth intervals from the surface and these slices presented as coloured line profiles and as conductivity-depth sections.

\section{Results and Discussion}

\section{Comparison of "in-river" NanoTEM and HEM conductivity responses}

An initial comparison of the mapped conductivity responses for both the NanoTEM and RESOLVE HEM data shows there to be good agreement (Figure 5), with the exception of minor anomalous noisy areas in the airborne data occurring in close proximity of the power lines. The in-river NanoTEM data is 
generally free of these artifacts. There are some minor differences between the two images shown in Figure 5, but this is attributed to the NanoTEM data representing the conductivity of riverbed sediments, whereas the RESOLVE data represents the 4 to 6 metre depth interval from the water level surface of the river. Differences may also be attributed to the footprints of the two systems.

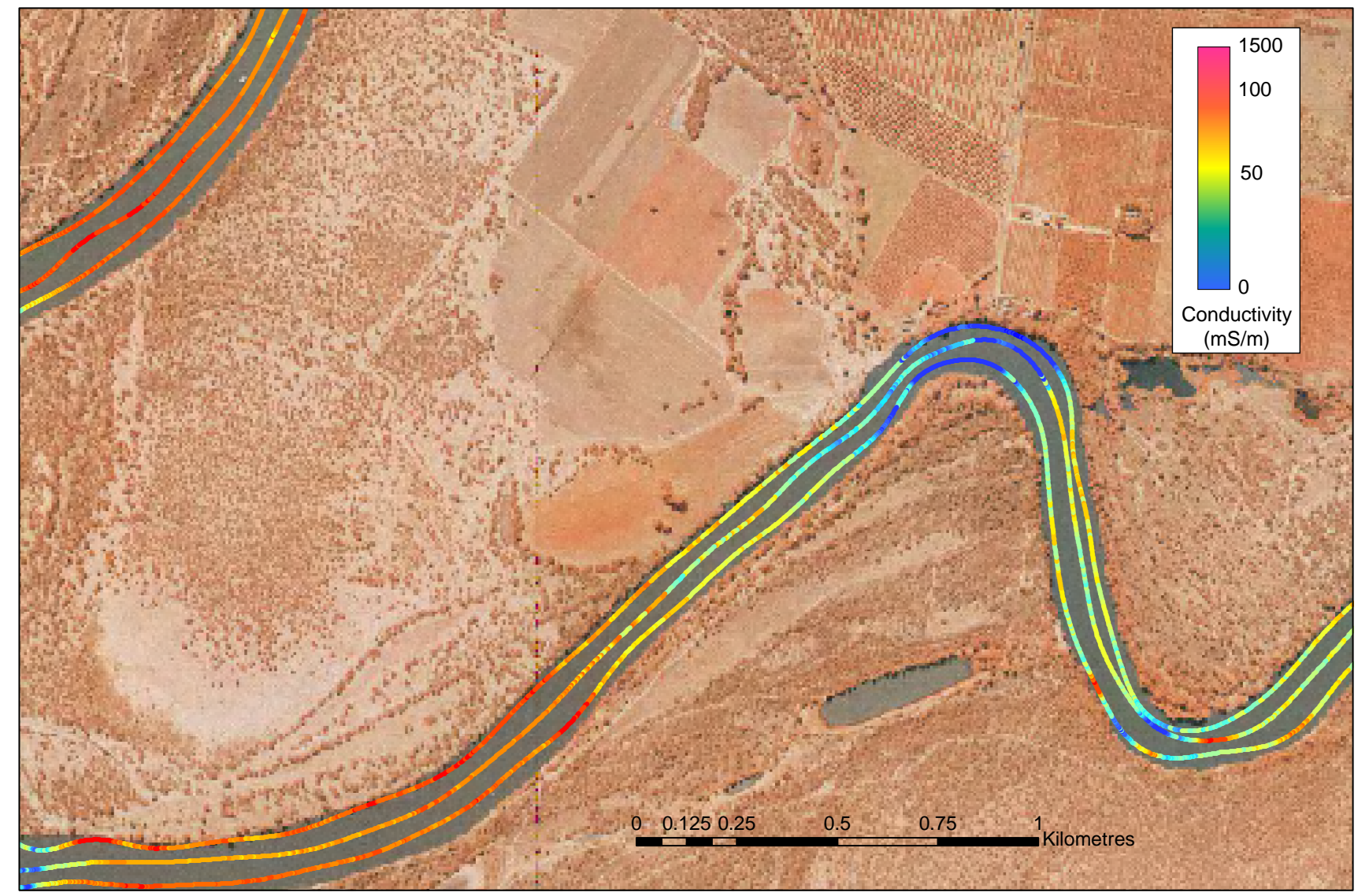

Figure 4: A section of the HEM "in river" survey illustrating the 3-line swath approach to mapping variations in salt stored in the river sediments and the variability of river-floodplain groundwater interactions along its course. The conductivity-depth interval shown is 4-6 $\mathrm{m}$ from the water surface.

The conductivity-depth sections derived from both the in-river NanoTEM and RESOLVE systems (Figure 6) also show a good agreement. The difference in depth of penetration is obvious when comparing the two systems. The depth penetration of the in-river NanoTEM is typically 20 metres, whereas the RESOLVE provides a greater depth of investigation up to 40+ metres in conductive areas. The vertical resolution of the NanoTEM system is greater than the RESOLVE although small subtle localized features are imaged successfully with both systems.

\section{Interpretation}

Both the mapped EM response and conductivity-depth sections show highly variable conductivity along the river course indicating varying surface water-groundwater interactions. Blue, resistive, areas predominant in the northern half of the survey (eg 893 to $903 \mathrm{~km}$ ) indicate 'losing' reaches of the Murray where the river is losing water to the regional groundwater system, and the riverbed sediments contain low salinity water. The red, conductive, areas correspond to 'gaining' reaches where base flow 
from the regional saline groundwater system discharges salt through the sediments into the river. The salinity of the regional groundwater will influence the salinity of the pore waters in the riverbed

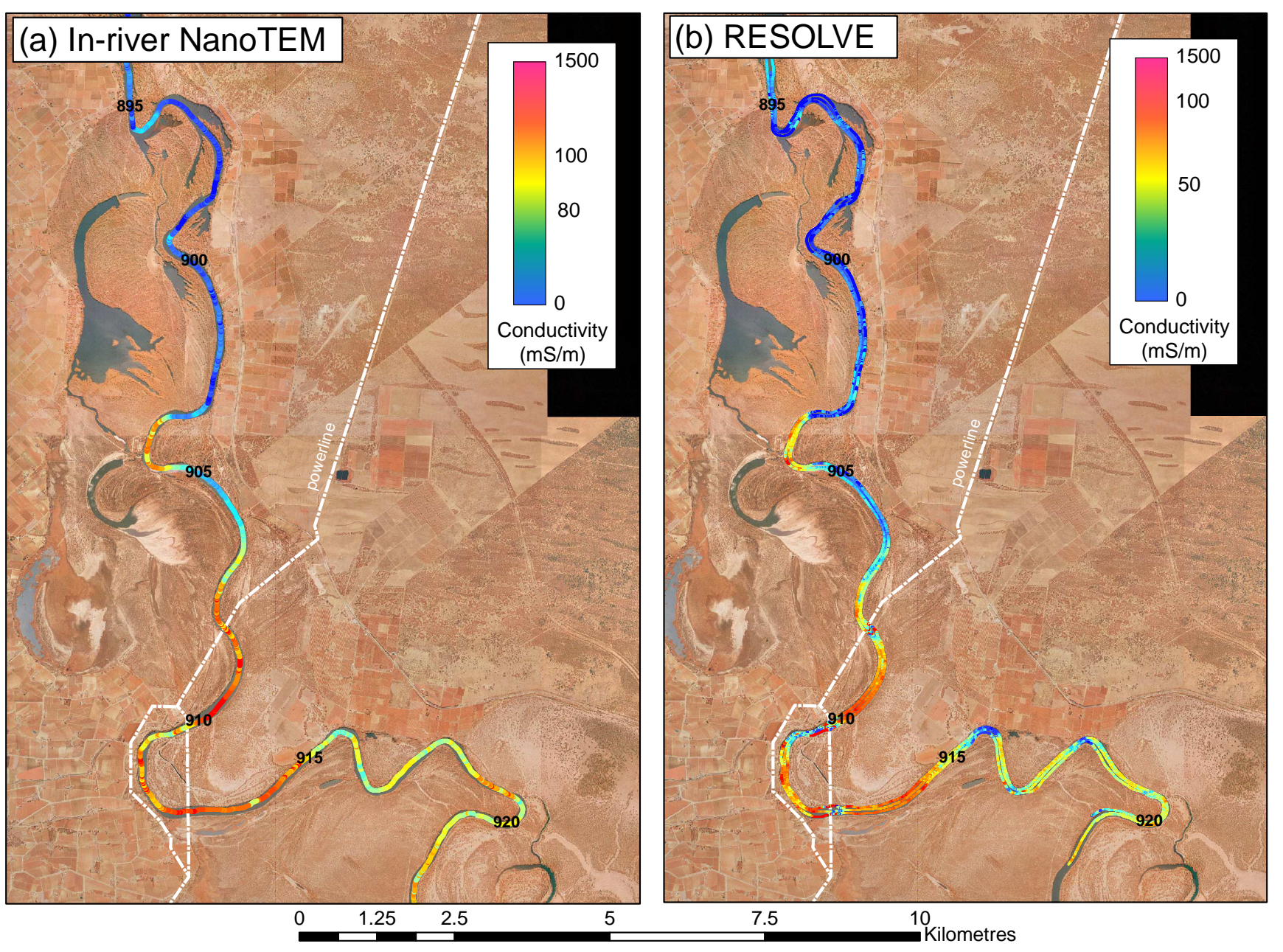

Figure 5. (a) Conductivity of river-bed sediments (top several metres) derived from the 2006 in-river NanoTEM survey. (b) Conductivity of 4-6 metre interval derived from the 2006 RESOLVE FDHEM data. The large power line running through the area results in noise in the airborne conductivity data, but the in river NanoTEM data is less affected. Numbers indicate river kilometers.

sediments where gaining stream conditions prevail. The salinity of the water table aquifer across Kings Billabong floodplain study area ranges between 18,000 and 30,000 mg/L. This provides a significant contrast to Murray water which approximates $300-500 \mathrm{mg} / \mathrm{L}$.

Interestingly, the HEM data also suggest that the connectivity between the regional groundwater system and the river may vary with depth. Modeled base flow from a steady state groundwater model for a floodplain with similar characteristics located 100 kilometres downstream (Doble et al., 2004) showed that where irrigation has been developed on highland areas adjacent to the floodplain, higher groundwater discharge (+ve baseflow) occurs into the river where it meanders close to the highland, and negative base flow is observed where the river meanders away from the floodplain-highland interface. These observations correlate strongly with the observed conductivities in both the NanoTEM and RESOLVE data for the Kings Billabong river reaches (Figures 5 \& 6). 


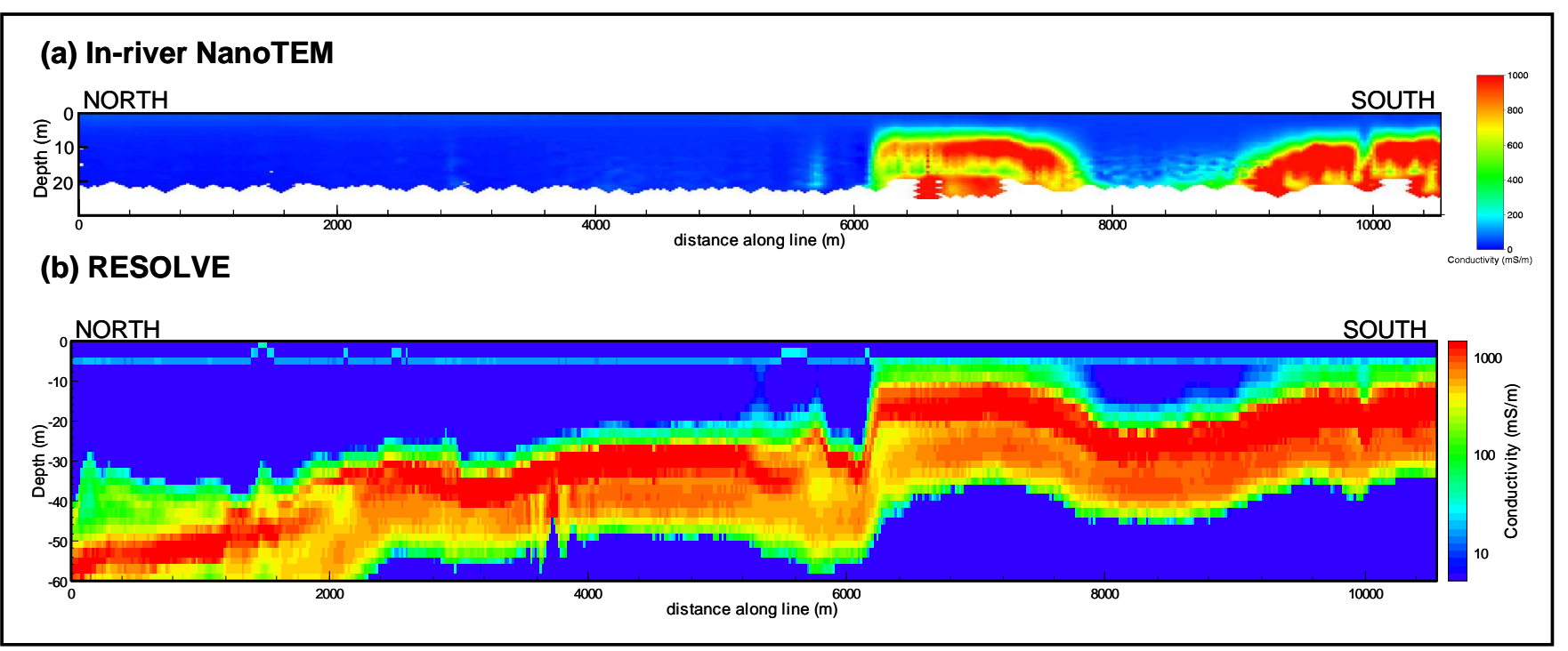

Figure 6. Conductivity depth sections for (a) in-river NanoTEM and (b) RESOLVE FDHEM data located between the 897 and 907 river kilometer marks (see Figure 5).

\section{Costs}

The cost differences between using in-river NanoTEM with RESOLVE can vary depending on survey design. In the simple case of traversing down the river, the cost for in-river NanoTEM is in the order of $\sim \$ 60$ per line $\mathrm{km}$ compared to $\sim \$ 120$ per line $\mathrm{km}$ for RESOLVE data. However, in the case where a swath survey plan is designed where ground NanoTEM might be collected in addition to the inriver data, then the cost becomes significantly higher, as ground NanoTEM surveying costs are in the order of $\$ 1000$ to $\$ 2000$ per line $\mathrm{km}$. A swath approach taken using an airborne EM system as shown in Figure 3 and Figure 4, would allow additional information on groundwater conductivity to be obtained in areas adjacent to the river. We believe this would add useful additional constraint in addressing processes of salinisation along the River Murray, and when used in combination with other data sets, would significantly add to our ability to assess and quantify the groundwater-river interactions which may not be apparent from in river data alone. With the addition of new salt interception schemes along the Murray, we contend that airborne data have the potential to help monitor their performance, and may assist in rapid assessment of changing floodplain-river conditions in times of flood or high flow conditions when in river survey methods have limited application.

\section{Conclusions}

The RESOLVE airborne electromagnetic system provided comparable results to in-stream NanoTEM surveys along the Murray River. Both NanoTEM and RESOLVE data were useful in identifying fine scale variations in base flow, showing alternation between losing and gaining groundwater in a river broadly understood to be a gaining system. While further detailed borehole and in-river measurements are required to gain a more accurate estimation of salt loads from the RESOLVE (and NanoTEM) data, the airborne approach shows potential for providing baseline information to assist the management and monitoring of floodplain systems long the Murray. We believe geophysical data of this type can be used to provide additional constraint to groundwater models, significantly improving our ability to predict the consequences of current and future salinity management practices. The main advantage with the airborne approach lies in the speed of acquisition. The results from this study may help determine the value and relevance of airborne systems in providing a snap-shot of the river's condition in certain time-critical situations - such as in a flood event. 


\section{Acknowledgements}

We would like to acknowledge all those who had a hand in the inception, development, support and conduct of the HEM survey in the Sunraysia area, and most particularly those at Fugro Airborne Surveys who assisted the trial of the RESOLVE system for the "in river" survey. In particular we thank Karl Mathers (formerly of Golburn-Murray Water), Phil Pfeiffer (Murray Darling Basin Commission), Glen Sutherland (Mallee CMA), Brett Johnson and Mike Lees (of Fugro Airborne Surveys) for their support in the conduct of this study.

\section{References}

Barrett, B., Heinson, G., Hatch, M., Telfer, A., 2005. A water-borne transient electromagnetic (TEM) system for river sediment salt-load detection, Journal of Applied Geophysics, 58(1), 29-44.

Doble, R.C., Walker, G.R., Jolly, I.D., Simmons, C.T., 2004. Methods of predicting the impacts of shallow saline groundwater on vegetation health using MODFLOW 2000 Proceedings of the $9^{\text {th }}$ Murray Darling Basin Groundwater Workshop, Bendigo, Victoria.

MacInnes, S. and Raymond, M., 2001. STEMINV Documentation - Smooth Model TEM Inversion, V.3.00, Zonge Engineering and Research Organization.

Macnae, J.C., King, A., Stolz, N., Osmakoff, A. and Blaha, A., 1998. Fast AEM data processing and inversion. Expl. Geophys., 29, 163-169.

Munday,T.J., Doble, R., Berens, V. and Fitzpatrick, A., 2006, The application of air, ground and 'inriver' electromagnetics in the definition of spatial patterns of groundwater induced salt accumulation in a salinising floodplain, lower River Murray, South Australia. Proceedings $19^{\text {th }}$ Annual SAGEEP Symposium on the Application of Geophysics to Engineering and Environmental Problems, Seattle Washington, April 2-6, pp 886-891.

Paine, J. Collins, E.W., Nance, H.S., and Niemann, K.L., 2006. Streambed induction logs: an airborne approach to identifying salinity sources and quantifying salinity loads. Proceedings $19^{\text {th }}$ Annual SAGEEP Symposium on the Application of Geophysics to Engineering and Environmental Problems, Seattle Washington, April 2-6, pp 96-104.

Porter, B., 1997. Run of River Salinity Surveys - Data Collection and Calculations Results and Recommendations: Department for Environment, Heritage and Aboriginal Affairs, South Australia, Natural Resources Division, Murraylands Region, Water Resources report 2/97.

Telfer, A.L., Palfreyman, C.J., Berens, V., and Hatch, M.A., 2004. Atlas of Instream NanoTEM 2004, Australian Water Environments Report 42417a. Prepared for the Murray Darling Basin Commission, Mallee Catchment Management Authority.

Telfer, A.L., Hatch, M.A., Woods, J., Baird, R. A. and Shintodewi, P., 2006. Instream NanoTEM Survey of the River Murray 2006: Wentworth to Torrumbarry - Lindsay-Mullaroo. Australian Water Environments Report No. 45755d. Prepared for the Murray Darling Basin Commission, Mallee Catchment Management Authority, Goulburn-Murray Water, North-Central Catchment Management Authority 